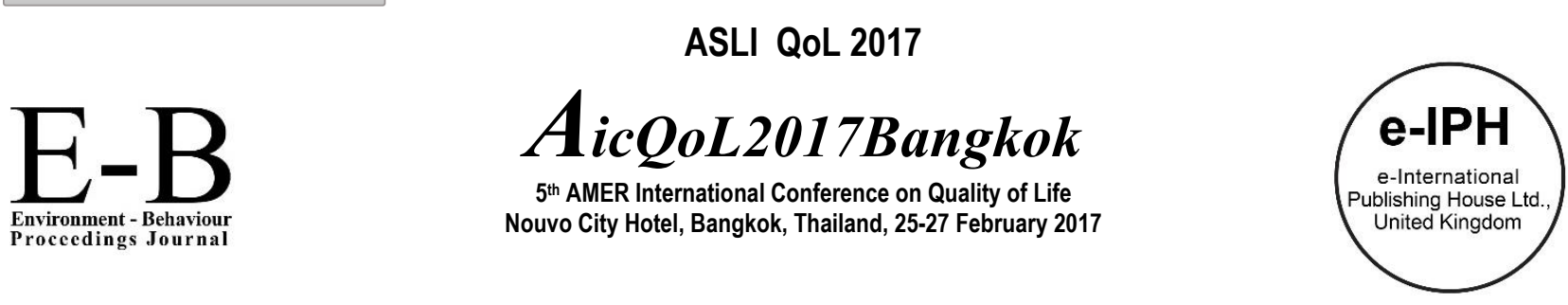

\title{
The Need for Good Social Behavior through People Friendly Urban Streets
}

\author{
Norhafizah Abdul Rahman ${ }^{1 *}$, Izham Ghani ${ }^{1}$, Azrul Bahaluddin ${ }^{1}$, Nur Huzeima Hussain 1 \\ 1 Faculty of Architecture, Planning \& Surveying, Universiti Teknologi MARA Perak, 32610 Bandar Seri Iskandar, Perak, Malaysia
}

\begin{abstract}
This paper explores the notion of people'-friendly streets. The primary concern is to identify the people's need for social behaviours on urban streets. The street environment is examined in respect of the physical qualities through the analysis of questionnaire surveys. Structured observations of the users' activities and physical environment of the street was conducted as part of the multi-method approach. The users' needs of a user- friendly street in the Malaysian context are mainly similar to the previous theories developed by other countries, especially the developed ones. However, the attributes that contribute to the factors vary for each context.
\end{abstract}

Keywords: Urban streets; social behaviour; people's need; people-friendly

ISSN: 2398-4287@ 2017. The Authors. Published for AMER ABRA by e-International Publishing House, Ltd., UK. This is an open access article under the CC BYNC-ND license (http://creativecommons.org/licenses/by-nc-nd/4.0/). Peer-review under responsibility of AMER (Association of Malaysian Environment-Behaviour Researchers), ABRA (Association of Behavioural Researchers on Asians) and cE-Bs (Centre for Environment-Behaviour Studies), Faculty of Architecture, Planning \& Surveying, Universiti Teknologi MARA, Malaysia.

\subsection{Introduction}

In Malaysian cities, it is hard to find examples of street environments that are friendly and accommodating to pedestrian users especially in the advent of motorised transportation. The unfriendly street environment for pedestrian in urban spaces is also cited as among the most critical urban issues addressed in the Kuala Lumpur City Plan 2020. Urban street designs in Malaysia have given priority to the needs of motor vehicles. This has resulted in street environments that are unfriendly to the people on foot that influence the erosion of the street as a public space, which also has an effect on public life and urban users. This research explores the notion of people-friendly urban streets. The primary concern is to identify the people's need for social behaviours on streets. The street will affect the people uses and activities that shaping the quality and character of urban living. There is a danger that the city will end up having streets which are not friendly to the various user groups if we do not understand the design criteria that fit with users' needs and preferences.

\subsection{Literature Review}

Good cities are places of social encounter (Mehta, 2013) and streets are streets are an important component of the urban form and the most public of the urban spaces in the city (Rahman et al., 2016, 2014). Creating urban streets that encourages social behaviours in our cities is one of significant goals in city design to create cities for people (Mehta, 2013). Streets are the main public space in urban areas. According to Jacobs (1996), when we think of a city, the first that comes to our mind is streets. The needs of the urban users are the most important quality to create successful urban streets. The actual needs and preferences in the street should be given more attention in order to re-evaluate the quality and design of the space over time (Jansson, 2010). In order to have an effective design and management of street, it is important to understand the role that those places play in people's lives and why spaces are used or ignored; why some work for people and some do not (Whyte, 1980; Carr et al., 1994). The needs of the users in the street depend on their activities in the street. Pedestrian activity or street life can be viewed as travel mode; pedestrian is defined as "one travelling on foot" (Owens, 1993). Street activities are more visible and prominent than activities that occur inside the building

\footnotetext{
* Corresponding author. Tel.: +6012-5141789

E-mail address: norha776@perak.uitm.edu.my
}

ISSN: 2398-4287@ 2017. The Authors. Published for AMER ABRA by e-International Publishing House, Ltd., UK. This is an open access article under the CC BYNC-ND license (http://creativecommons.org/licenses/by-nc-nd/4.0/). Peer-review under responsibility of AMER (Association of Malaysian Environment-Behaviour Researchers), ABRA (Association of Behavioural Researchers on Asians) and cE-Bs (Centre for Environment-Behaviour Studies), Faculty of Architecture, Planning \& Surveying, Universiti Teknologi MARA, Malaysia.

DOI: http://dx.doi.org/10.21834/e-bpj.v2i5.710 
and concentration of the activities on street and their visibility from the street are important in order for the place to be noticeable and more attractive (Shamsuddin, 2011). However, according to Appleyard (1983), most of the streets are killed by the automobile for which they were built; from a social viewpoint, they are dead places.

Outdoor activities in public space can be divided into three categories: necessary activities (going to school or work, waiting for a bus or a person, shopping, etc.), optional activities such as taking a walk, standing around enjoying life, or sitting) and social activities such as children at play, greeting and conversation, seeing and hearing other people (Gehl, 1987; Turel et al., 2007). Meanwhile, Rapoport (1987) divides pedestrian activity into two principle types: dynamic and static. Dynamic activities comprise walking, strolling and running, while static activities include standing, sitting, squatting, working and talking. Pedestrian street life and activities are not only affected by the physical variables but perceptual and cultural variables as well (Rapoport, 1987). Gehl (2010) argued that the categories of outdoor spaces are influenced by the quality and the character of the outdoor space. He adds that the activities and functions will be developed when the qualities of the space are improved (Gehl, 2010).

User-friendly relates to the theory of inclusive environments of a street where accessibility, safety and usability are the framework for inclusive design (Yaakub et al., 2009). In the case of a street, an inclusive street is a street that can be used by all groups of people regardless of age and ability. Users of the street environment are anyone who is interested in their local environment and streets (Burton et al., 2006). A review of related literature suggests that there are three major criteria that contribute to a friendly street: physical qualities, activities or functional qualities, and social qualities. All this gives meaning to the street that makes the street friendly or not. The presence of a variety of people on the street contributes to the variety of activities taking place on the street. A mixture of activities and use can create a successful community and public space that enables the street to attract more people to come (Shamsuddin, 2011). Hence, she adds that the benefits of mixing use and activities are that there will be a better choice for social interaction, visual stimulation more effective use of spaces and buildings, a variety of users and a secure environment due to the presence of 'eyes on street'.

\subsection{Methodology}

This study adopts a case study method that is approached in both qualitative and quantitative manner. The street environment is examined in respect of the physical qualities through the analysis of questionnaire surveys of 346 respondents selected using quota sampling. The respondents were broadly divided into daily users (those who are constantly engaged with the street) and occasional users (those who are not dependent on the study area. The daily users (shop owners, shopkeepers, vendors, office workers) were selected based on the systematic sampling method using the interval of unit spaces on the ground level of the street (shopping space, restaurants, stalls, stores and shop premises). In this sampling the total of the units within the street of JTAR is divided by the total number of sample size required. Based on observation on site the number of unit spaces is 346, which is divided by 170 (the total number of sample size required). Therefore, the selection of respondents is based on an interval of 2 units.

In this study, structured observations of the users' activities and physical environment of the street was conducted as part of the multi-method approach to record the physical characteristics and the qualities in urban pedestrian environments and to study human activities on the streets. Field observations and documentation of the quality of the site in the form of maps and photographic records were conducted for each sub-area of the case study. Field notes and related photographs were taken of all major elements in the space; buildings use, and landscape use with the physical settings. The data were processed using both qualitative and quantitative approaches and tabulated to find potential patterns and connections. The results from the physical observation and activities observations were used to support the results revealed from the questionnaire surveys. Triangulations were made within and between other data from observation of physical characteristics and activities on the street, interviews and from previous researchers in the literature review.

\subsection{Case Study}

Jalan Tuanku Abdul Rahman is well known as one of the earliest routes in Kuala Lumpur and as one of the earliest traditional shopping districts in Kuala Lumpur. Jalan Tunku Abdul Rahman (JTAR) is identified as one of the main traditional streets in the city centre due to its inherent socio-cultural role and historical significance as being among the earliest high-streets in the city centre of Kuala Lumpur (Shamsuddin et al., 2010).

Jalan Tuanku Abdul Rahman was noted for 'shophouses', a typical character of the Malay urban settings in the nineteenthcentury. As the city grew, 'shophouses' were developed in groups with facades of unified designs. Such grouping arose from the need to provide covered pedestrian passages along the shops and from an understanding of scale and civic responsibility. The initial, simple design slowly became increasingly elaborate in the details and decoration. As the 'shophouse' unit came under the control of individual owners many have been and continue to be remodelled and replaced by larger buildings. This street receives the highest concentration of shoppers, visitors and pedestrians $(\mathrm{KLCH}, 2003)$ and is located in the area which has been dedicated for urban revitalization initiative (Ujang, 2012).

\subsection{Results and Discussion}

In this paper, the factors that make a street friendly related to how they use the street, what make them use or not use the street, and what would encourage people to use the street more? As mentioned in the literature review, to evaluate a user-friendly street, it is important to examine the actual uses and activities and their preferences towards the street. 


\subsection{Users activities on street}

The reasons for use may affect the activities on the street. The results from the surveys indicate that in the context of JTAR, the functional factors were the main factors that influence the use of the street. This street indicates a significant function in supporting the economic and social activities. Users' activities on the street were very much dependent on their reasons for using the street and also concerning the quality of the environment (Gehl, 2010). Meanwhile, the differences concerning how they used the street were affected by the types of activity and the reasons they used the street. The feedback on this is important to determine the factors that make them use the street and at the same to justify different factors to cater for different activities.

In order to identify the reasons for using the street in JTAR, the respondents were asked questions regarding the street that they normally used and the reasons they used the streets in Kuala Lumpur in general. In this research, the respondents were also asked about the streets that they most visited in Kuala Lumpur city centre and the main reasons why they used those streets. This was to get the overall trend of the reasons they used the street. Based on the feedback from the survey on the streets that they usually used in Kuala Lumpur city centre, the streets most mentioned included JTAR, Jalan Bukit Bintang, Jalan Masjid India, Jalan Ampang, Jalan Hang Tuah,Jalan Imbi, Jalan Duta and Jalan Pudu. This proved that Jalan Tunku Abdul Rahman was one of the most significant and popular streets used in Kuala Lumpur city centre. This shows that JTAR was one of the most popular and significant to Kuala Lumpur residents. The feedback from this survey indicated that the most popular reasons they used the streets in Kuala Lumpur were for working, live there, shopping, its proximity, leisure and using the public transport services in that street. The results show that the majority of the users used the street for necessary purposes like working, live there and using public transport (transit area) (refer Fig. 1).

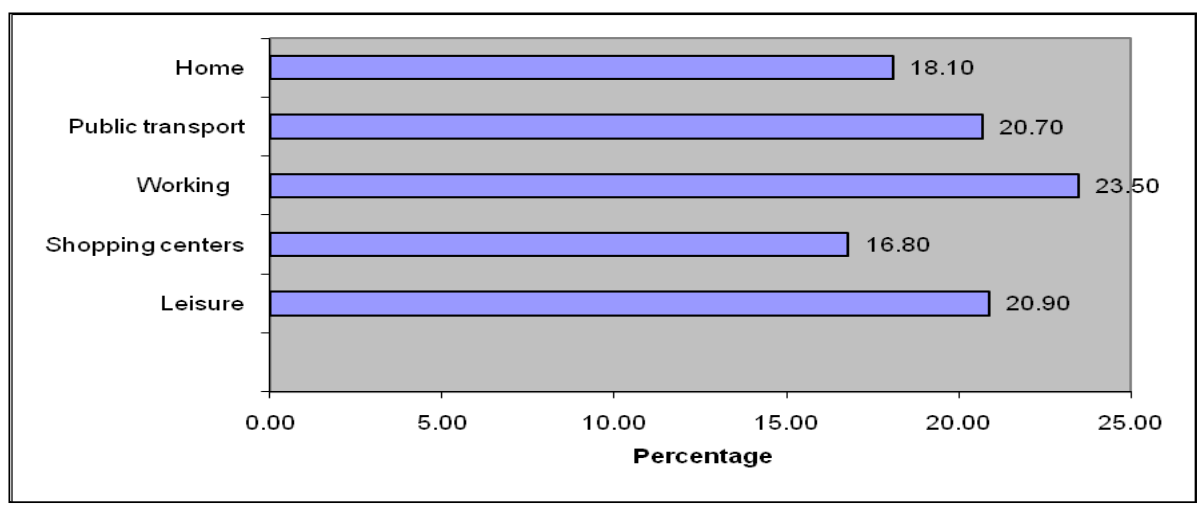

Fig. 1: The reasons for using the streets in Kuala Lumpur

(Source: Author's field survey, 2009)

In order to identify the reasons for using the street in JTAR, the respondents were asked questions regarding the street that they normally used and the reasons they used the streets. Based on the questionnaire survey of the occasional users (refer Table 1), the most frequent reason they use JTAR is for shopping (30.1\%). This can be associated with JTAR as a shopping street and shopping was the main attraction in the city centre. Based on observations on the site even though there are different types of development, the most vital generators are business and commercial activities. This is supported by the feedback from the interviews and from the statement by (Shamsuddin et al., 2010) in their study on JTAR in which the majority of users use the street for shopping purposes.

Table 1. The most frequent reasons for street usage by users in JTAR

\begin{tabular}{lll}
\hline Reasons & Frequency $(\mathrm{N}=161)$ & Percentage $(\%)$ \\
\hline Shopping & 48 & 30.1 \\
Working & 12 & 7.5 \\
Visiting & 18 & 11.4 \\
Meeting friends & 32 & 20.0 \\
Relaxing & 10 & 6.5 \\
Studying & 9 & 5.3 \\
Entertaining & 14 & 8.6 \\
Live there & 17 & 10.3 \\
Others & 1 & 0.3 \\
\hline \multicolumn{2}{c}{}
\end{tabular}

The results from the observations survey on the activities in JTAR (Fig. 2) found that nodes of activities were more focused around shopping areas. The most popular nodes were the Uda Ocean (UO) Superstore area, Mydin area, Maju Junction area, SOGO area, Gulati's area and Kamdar area which are shopping complexes and areas selling textiles. It was found that during observation, shopping activities were more during weekends and the intensity of people was very high around the UO superstore area and the SOGO area spreading to Pertama Complex (Fig. 2). Responses from the interviews indicate that a variety of choices, diversity of products and distinctive products that they can get from this street make them love to shop here. Based on the observation on site, people met friends together enjoying food in restaurants or shopping together. The presence of outdoor cafes and restaurants that 
provide wireless Internet and air conditioning make the place suitable as a meeting place for people. Other activities such as visiting, relaxing and entertaining were optional activities that were present in JTAR. The results concerning the purpose for using the street in Kuala Lumpur also showed that the users also used the street for the purpose of 'hanging during their free time.

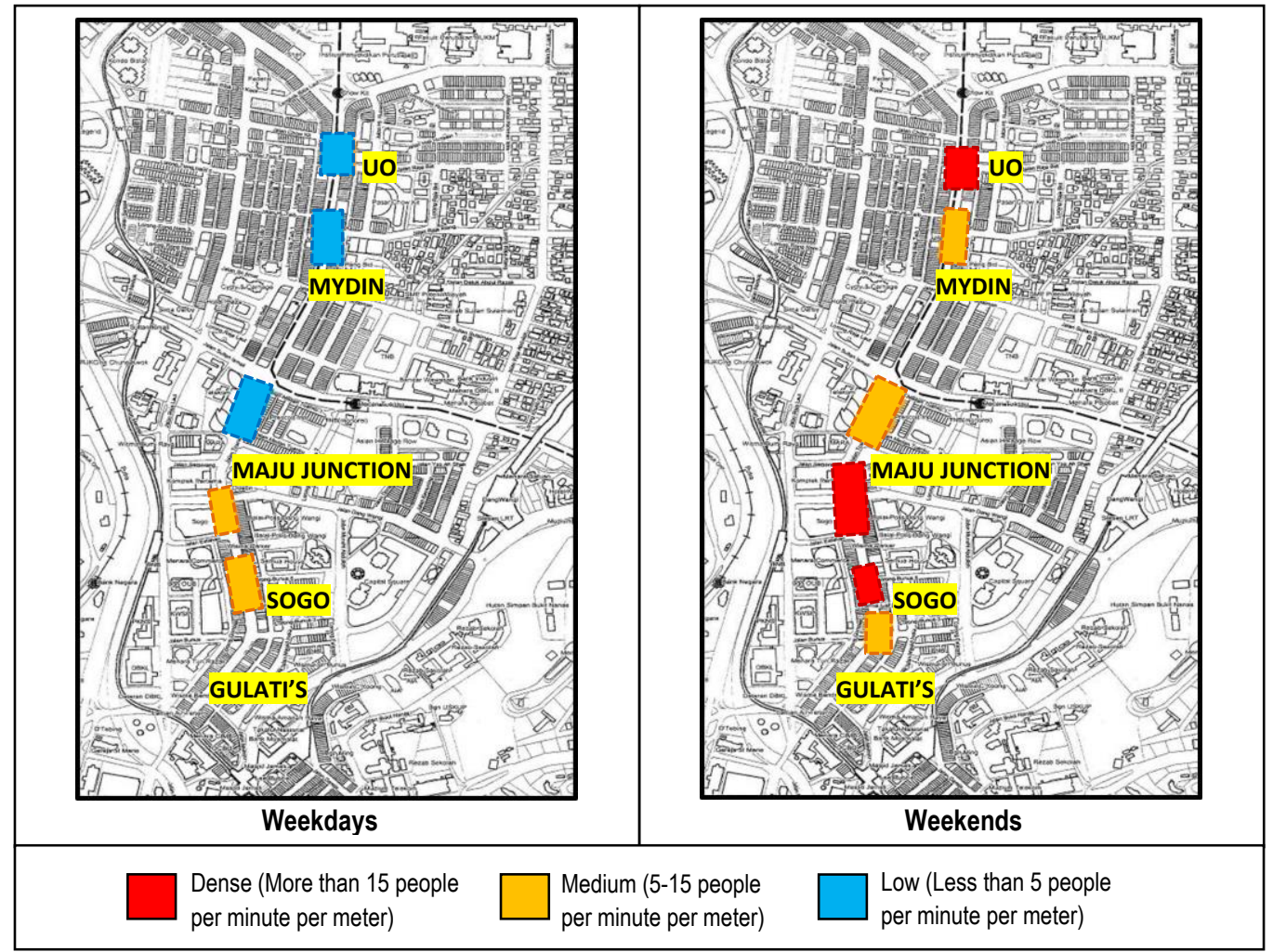

Fig. 2: Nodes of activities during weekdays and weekends (Source: Authors)

In this research, the respondents were asked their preferences for using JTAR during their free time. This was to identify whether or not the street is used for optional or social activities. The feedback from the occasional users shows that, 55.6 per cent like to come to JTAR during their free time. This shows that the street is also a place for leisure activities. When talking about leisure it must be related to their optional and social activities in the street.

The occasional users were also asked about the reasons they used JTAR during their free time. The reason why only the occasional users were asked is because it is less relevant to ask daily users as they use the street no matter what. Hence, based on the survey of daily users they were mostly involved with necessary activities, which, according to Gehl (2010), were less sensitive to the surrounding environment compared to the occasional users. Most of them come here during their free time for leisure (33\%), using the facilities (27\%) and shopping (25\%). From site observation, the leisure related to dominant buildings such as Sogo, the Pertama Complex and Maju Junction, where it was observed that the people used the places for sitting, meeting and walking. However, in the case of JTAR it was found that most of the social activity appeal was passive contacts like seeing and hearing as Gehl (2010) said as 'superficial'. A pleasing environment is one of the sub-factors that can attract activities onto the street and one of the criteria that support user-friendly factors. In this research, the respondents were asked about the actual environmental quality of the site. The results of the survey concerning the degree of visually pleasing places in JTAR show that there was a moderately positive response from users' perceptions concerning the quality. There was a slight difference in users' perception between two types of user towards the street's "pleasing environmental quality". This shows that visually pleasing place is one of the factors that can attract people to use the street. This was proved by Gehl (2010) in that there is a strong connection between the qualities of the physical environment on site. Gehl (2010), in his research, found that an increase in environmental quality will give a boost to optional activities and at the same time will increase the social activities.

Based on the reasons they used the street we can say that most of the activities in JTAR were among the necessary activities such as shopping, working, living there and studying. Meaning that, the awareness concerning a 'friendly street' from the users under necessary activities was lower compared to the group that came to the street for optional and social activities. The others come for 'optional activities' (Gehl, 2010), such as visiting friends, relaxing and entertaining. This result supports the theory from Gehl (1987) that the necessary group constituted the majority related to walking. That was also the reason why the daily group were more concerned with the environmental condition compared to the occasional users. However, these groups are more or less independent of the exterior environment because they have no choice. For the group doing optional activities, they used the street because the 
exterior conditions are optimal for them, when the weather and place invite them. These activities are dependent on exterior physical conditions. Most of them use the street because they have to use it. This was reflected in most of the respondents' statements when they described shopping and meeting friends as the main reasons they use the street.

The understanding of the activities that occur in the street is important to generate new ideas and also for proposing new development that is friendly to their users. This is in line with Shamsuddin et al. (2010), who stressed that the designers are highly recommended to look into the activities in the urban spaces in order to exploit for future design.

\subsection{Supporting factors that make people use the street}

Based on users' suggestions concerning the improvements needed in JTAR, the public facilities, such as interesting public spaces, improvement to public facilities (toilets, signage and dustbins), seating, greenery and trees, parking, maintenance and activities. The findings are also supported by Ujang (2012) in her physical observation that identified that along JTAR is lacking with greenery, landscape elements, pedestrian facilities and poor surface and maintenance of pedestrian walkway. As for the daily user group, the main reason they used the street is included less congestion, interesting public places, good maintenance, greenery and activities on the street. This group was the one that used the street most, was familiar with the street and valued the street. Consequently, they were more concerned with improvement of the environmental condition making it more pleasant and comfortable - rather than the safety factor.

\subsubsection{Public space}

It was identified that public space is one of the elements in JTAR that needs improvement. The results from the survey indicate that the respondents need interesting public spaces. The results of the survey show that the daily group of users mentioned the need for improvement of the public spaces along JTAR the most. This is because this group comprises the users that spend more time in JTAR, and, therefore, need a space that interests them for leisure purposes. JTAR has a rich public realm in which the shops, offices and restaurants offer leisure facilities to the public. As for gender groups of user, the male groups of users indicated the need for improvement of the public spaces along JTAR more compared to female group of users (Fig. 3). These according to the observation due to the majority of users who spend more time in outdoor spaces and involved more in outdoor activities are male group of users. This finding concur with Loukaitou-Sideris (1995) and Sisiopiku et al. (2003) who found that female are the minority group that use urban space.

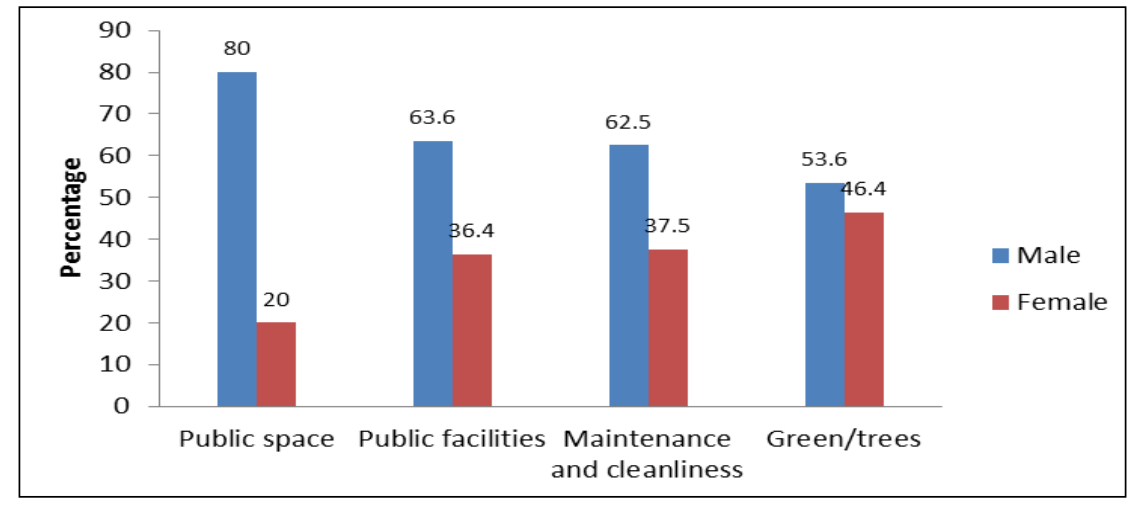

Fig. 3: Factors that make the users use the street by gender (Source: Authors)

Based on the observations, this place was only used by people during festivals when they built temporary kiosks to sell things and every Saturday night when there is a night market nearby. From observation, it was identified that Laman Tuanku Abdul Rahman is sunken from it surrounding, which gives a feeling of insecurity when using this space due to the lack of pedestrian surveillance (Fig. 4). Whyte (1980) argued that locating spaces away from the street level, like sunken spaces or rooftop urban space is not convincing in terms of safety. Hence, the presence of undesirable people, such as beggars and the homeless, the hedges that block the view from the street, and bird droppings everywhere contribute to the feeling of discomfort to the users. As Whyte (1980) noted, public users are not only frightened by criminal acts in urban spaces but also by 'undesirables'. 


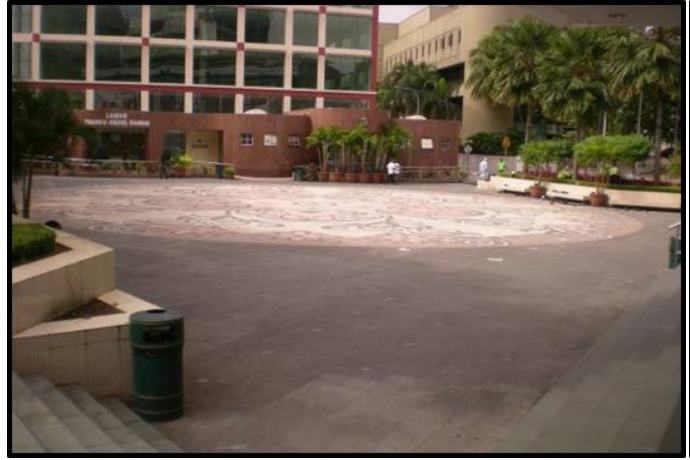

(a)

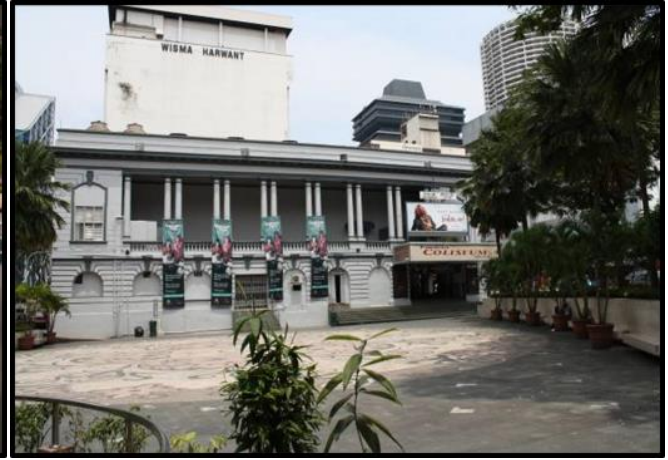

(b)

Fig. 4. (a) and (b) Laman Tuanku Abdul Rahman (Source: Authors)

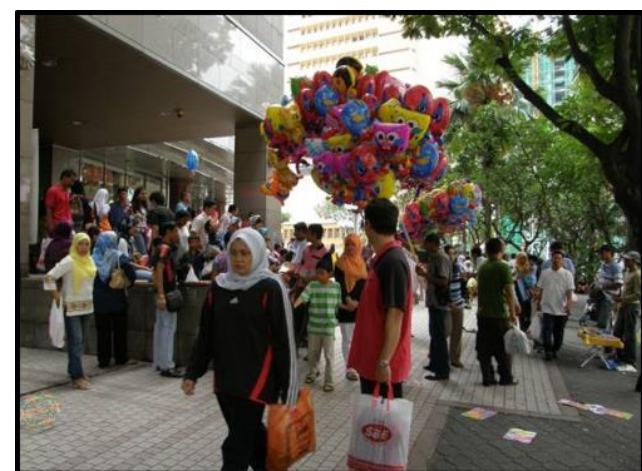

(a)

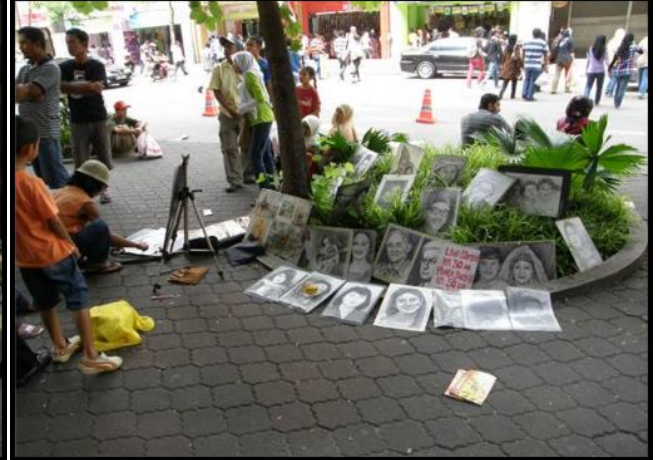

(b)

Fig. 5. (a) and (b) Open space in front of SOGO shopping complex (Source: Authors)

It was proven by observation that the presence of people and activities in a space can attract other people to use the space. This was proven by the observation of the SOGO area. Unlike Laman TAR, the small square in front of the SOGO shopping complex contributes a vibrant public space with musicians, salesman, hawkers selling food and drinks and individuals handing out brochures and flyers (Fig. 5).

\subsubsection{Greenery}

It was found in survey of JTAR that, trees and greenery along the street do affect the uses of the street. In the case of JTAR, there is strong exposure to the sun every day, therefore tree planting is one of the provisions for providing shade, reducing glare and cooling the atmosphere. The presence of trees/ greenery was felt to have a positive effect on the environment, such as modifying the impact of the microclimate, providing shade from the sun and also acting as a divider between the pedestrian walkway and traffic flow. This is supported by the observations in JTAR where only certain zones have been planted with trees. It was observed that in the areas that have shaded trees planted, more activities exist (Fig. 6). The seating located under shady trees also show more use by the street users compared to the seating located in the bare area along the street (Fig. 7).
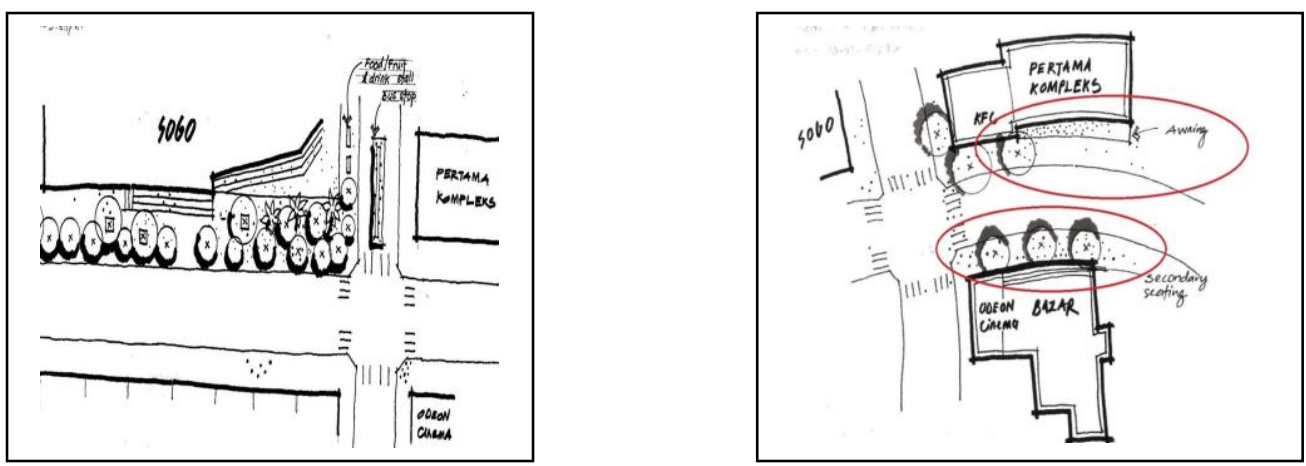

Fig. 6: People use shade from the awnings and trees to get shelter from the sun (Source: Authors) 


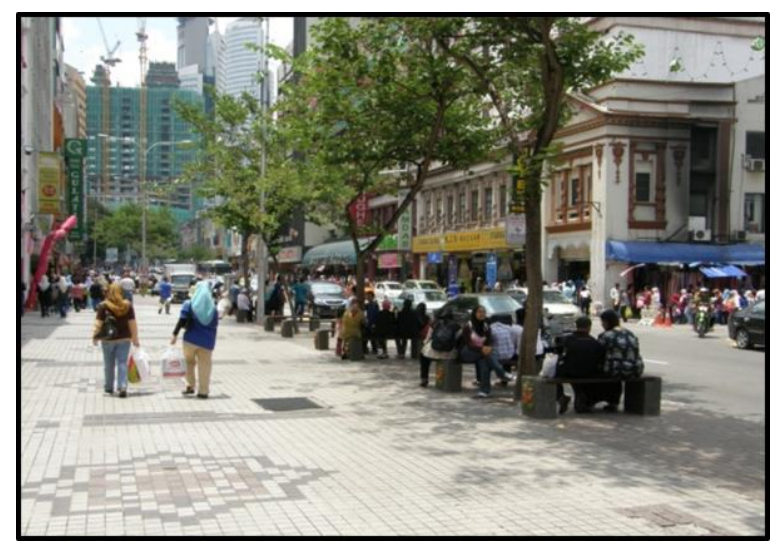

Fig. 7: The static activities happening in the area that provide shade (Source: Authors)

However, in some locations in JTAR some of the trees provided are unsuitable for shade because they are not big enough or lack of dense canopy. This is because some of the species of the trees planted are unsuitable for shade purposes (Fig. 8). Based on observation in JTAR, although there are trees provided along JTAR, only some places are shaded because in most parts the trees are not big and the canopies of the trees are not dense enough to provide shade for the pedestrians. In some part of the street palm trees have been planted which do not provide shade for pedestrians. The important of green areas was also supported in Achariam (2011) research who found that, the feedback from respondents that need to be resolved and need attention is having more green areas in the city centre.

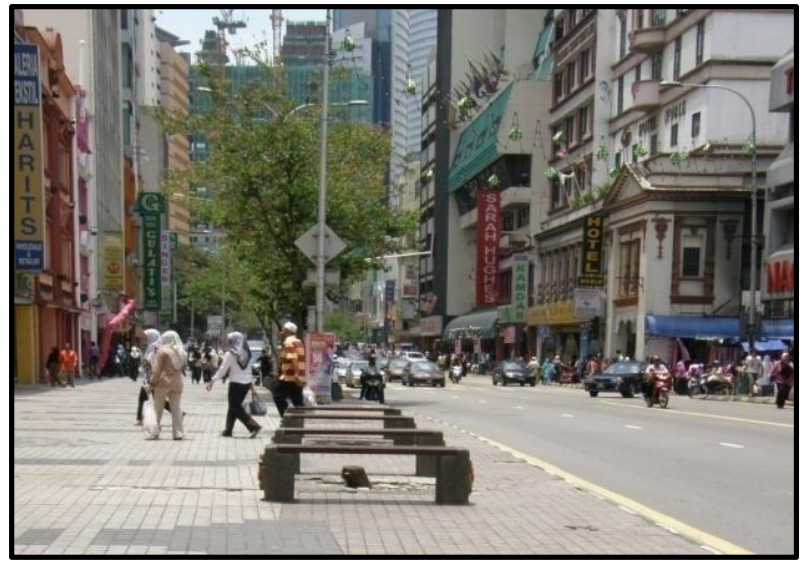

(a)

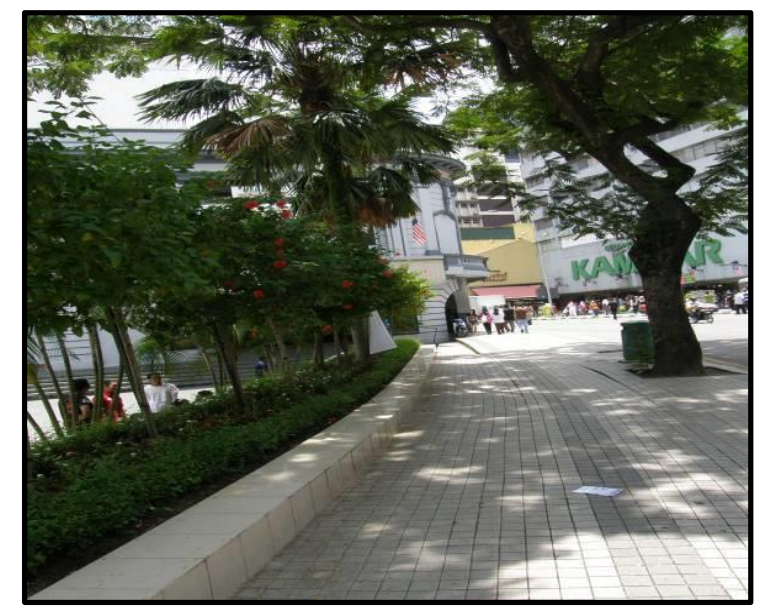

(b)

Fig 8. (a) and (b) Different size and density of tree canopy provide different level of shade (Source: Authors)

It has been proven in previous studies that relief from the sun is also a main factor that needs to be considered, as it can affect the microclimate in urban spaces (Whyte, 1981; Carr et al., 1992). Unlike Western and European countries where the sunlight penetration into places helps make the area more pleasant to the users (Carmona et al., 2003), in the Malaysian context, the protection from sunlight is a crucial element that can make people feel comfortable and pleasant when using the street. The results from the survey concerning the improvements needed in JTAR reveal that providing covered walkway, trees and greenery which relate to protection from the sun and rain and also cooling aspect are required. This is in line with the statement by Lynch (1981) that streets that are shady provide a setting for activities and can bring people together.

\subsubsection{Public amenities}

A public amenity is another factor that needs to be taken into account in creating a user-friendly street. Based on the survey, this is one of the factors that are lacking and needs improvement in JTAR. Lack of public amenities is one of the main reasons people do not use the street. This is supported by the results of the survey, which shows that the non-user group constituted the highest percentage that indicated the need for improvement of the public amenities in JTAR. This factor is also revealed as one of the attributes that contribute to a user-friendly street. Facilities on the street such as dustbins, telephones and toilets are among the attributes perceived by respondents as being the most important to create a convenient street and at the same time contributing to a friendly street. 
JTAR has a number of street furniture and pedestrian facilities provided for the pedestrians as well as a police booth. Based on the observation, signage and cues are also provided along JTAR. However, all these elements should be more in number and more legible to the pedestrians that walk along the street. JTAR has seating, ledges and stairs for pedestrians to sit or rest, however, the amount of seating is still lacking. Public toilets are also provided along this street. The presence of all these public facilities gives the feeling of convenience to the street users in JTAR. However, the numbers, qualities, maintenance and location of the facilities should also take into consideration. Based on observation in some areas along the street, to the location of such facilities is not appropriate causing a blockage and creating clutter for pedestrian movement. Hence, some of the facilities provided along the street are not sufficient (e.g. dustbin and telephone booth), not function (e.g. telephone booth) and not well maintain (e.g. public toilets) that gives inconvenience to the street users. The maintenance issue will be discussing in the sub-section as one of the supportive factors that make people use the street.

\subsubsection{Maintenance and cleanliness}

Good maintenance and cleanliness of the street was another factor that users need most on the street. This shows that maintenance and cleanliness are one of the significant factors that contribute to a friendly street. This is supported by the results of the survey concerning the suggestions for improvements needed to JTAR as this factor became one of the significant factors needed to improve JTAR. Based on the observation on the site studied, it was proven that there were some areas along JTAR that were not well maintained and were poor in terms of cleanliness (Fig. 9). This not only gives a bad impression and bad views to the street users but also creates the feeling of a lack of safety and discomfort to the street users. The feedback from one tourist (Korean) to our streets is that in some areas, the pedestrian walkways are not well maintained, which make it unfriendly to the users. This is also supported by the feedback from the users' perceptions of streets in the UK. It was found that the streets most chosen by users in the UK are streets that are clean and well maintained (Carmona et al., 2003).

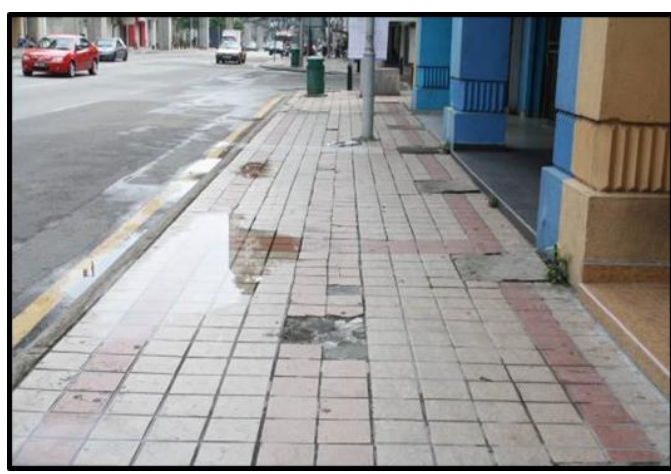

(a)

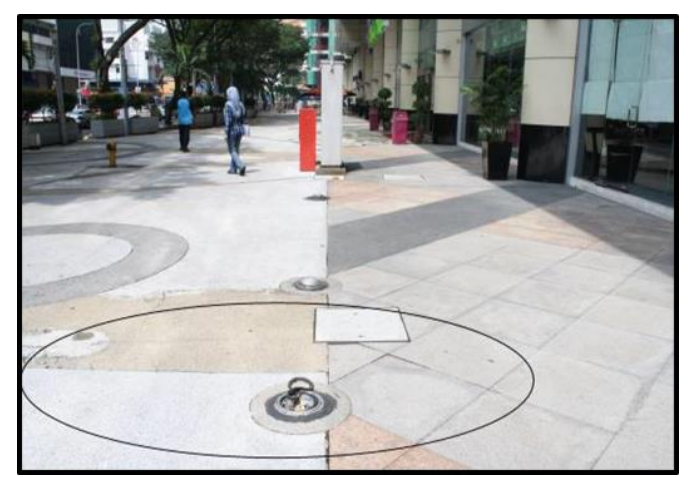

(b)

Fig. 9 (a) and (b): Lack of maintenance of pedestrian walkway in JTAR

(Source: Authors)

\subsubsection{Freedom of action}

The results from the survey (Table 2) indicate that the majority of the users agreed that JTAR provides an opportunity to interact with each other. Most of the respondents from the occasional and daily groups feel that JTAR is a street that provides an opportunity for them to interact with each other. However, for non-users, $45.6 \%$ of them answered differently. This may be because they do not use JTAR. This is supported by Rivlin (1994) in that freedom of action in public space is one of the important factors that contribute to a good space. Freedom of action is related to spatial rights, as, according to Lynch (1984), it is related to behaving freely in a place.

Table 2. Opportunity to interact with each other

\begin{tabular}{lll}
\hline Provides an opportunity to interact with each other & Frequency ( $\mathrm{N}=345)$ & Percentage (\%) \\
\hline Yes & 270 & 78.3 \\
No & 75 & 21.7 \\
\hline \multicolumn{2}{c}{}
\end{tabular}

Meeting personal needs also contributes to the freedom of action that relates to the use of the street. Freedom of action is also about satisfying personal needs (Carrs et al., 1994). Different types of user have different needs. The results of satisfaction on users personal needs show that occasional groups gave the highest percentage $(69.7 \%)$, which said yes followed by daily user in which 56.8 $\%$ of them said yes. Unfortunately, the majority (68.4\%) of the non-users answered that JTAR did not satisfy their personal needs (Fig. 10). In respect of this feedback, we can say that personal needs are important to make the users use or not use the street. This is supported by Shamsuddin (2007) who stated that user-friendly is related to the functional balance between human needs and environmental factors. In addition, meeting the users' actual needs is important to evaluate the quality of the street that is friendly to them (Jansson, 2010). 


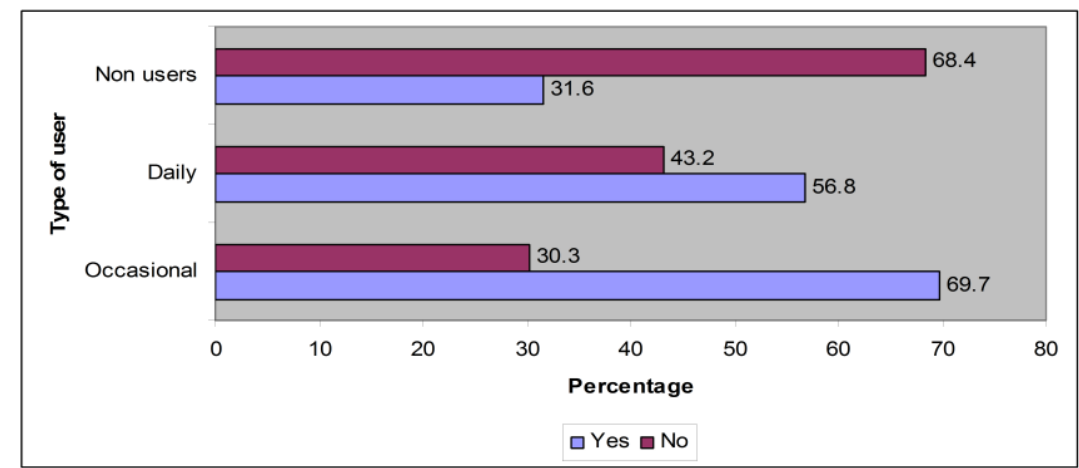

Fig. 10: Satisfy personal needs

(Source: Authors)

\subsection{Conclusion}

In this paper, the factors that make a street friendly related to how they use the street, what make them use or not use the street, and what would encourage people to use the street more? A user-friendly street will facilitate the creation of a walkable environment that is seen as the more sustainable approach towards city planning and design in the future. The findings revealed that the user needs of a user- friendly street in the Malaysian context are mainly similar to those developed by other countries, especially the developed ones. However, the attributes that contribute to the factors vary for each context, especially between countries with different climate and economic level (developing and developed countries). This paper identifies the factors that need to be considered in future guidelines and policies for the planning and design of urban spaces, in particular for streets in city centre to create a user-friendly street environment. It is hoped that these factors will be taken into consideration by those involved in the decision- making process concerning urban planning and design.

\section{References}

Abdul Rahman, N., Md Sakip, S. R., \& Mat Nayan, N. (2016). A user-friendly shopping street. Asian Journal of Environment-Behavior Studies, 7(27).

Abdul Rahman, N., Md Sakip, S. R., \& Mat Nayan, N. (2016). Physical qualities and activities for a user-friendly shopping street in the context of a Malaysian city. Procedia - Social and Behavioral Sciences, 222, 196-202.

Abdul Rahman, N., Shamsuddin, S., \& Ghani, I. (2014). What makes people use the street?: Towards a liveable urban environment in Kuala Lumpur City Centre. Procedia - Social and Behavioral Sciences, 170, 624-632.

Abdul Rahman, N., \& Md Sakip, S. R. (2014). Relationship between accessibility and safety criteria with the uses of the street: A case study of urban commercial street in Kuala Lumpur city centre. [Online]. Available:

https://www.academia.edu/15827062/Relationship_between_accessibility_and_safety_criteria_with_the_uses_of_the_street_A_case_study_of_urban_commercial_stre et_in_Kuala_Lumpur_city_centre [2016, 12 October].

Achariam, N. (2011). KL City Plan 2020 to be gazetted in July. New Straits Times [Online]. Available: www.nst.com

Carr, S., Francis, M., Rivlin, G.L., \& Stone, A. M. (1992). Public space. USA: Cambridge University Press.

Carmona, M., Heath, T., Oc, T. \& Tiesdell, S. (2003). Public places, urban spaces: The dimensions of urban design. London: Architectural Press.

Gehl, J. (2010). Cities for people. Washington: Island Press.

Gehl, J. (1987). Life between buildings: Using public space. New York: Van Nostrand Reinhold.

KLCH (2003). Kuala Lumpur Structure Plan 2020. Kuala Lumpur: Kuala Lumpur City Hall.

Loukaitou-Sideris, A. (1995). Urban form and social context: Cultural differentiation in the uses of urban parks. Journal of Planning Education and Research, 14, 89-102.

Lynch, K. (1984). Good city form. Cambridge, MA: MIT Press.

Rapoport, A. (1986). The use and design of open spaces in urban neighborhoods. In A. Rapoport \& D. Frick (Eds.), The quality of urban life (pp. 159-175). New York: Walter de Gruyter \& Co.

Shamsuddin, S., Abdul Rahman, N., \& Sulaiman, A. B. (2010). How walkable is our city? Its influence in creating sustainable city centre design. Paper presented at the International Conference Sustainable Architecture \& Urban Design 2010, Universiti Sains Malaysia, Malaysia.

Ujang, N. (2012). Place attachment and continuity of urban place identity. Procedia - Social and Behavioral Sciences, 49, 156-167.

Whyte, W. H. (1981). The social life of small urban spaces. Washington D.C.: The Conservation Foundation. 